\title{
Migration Paths of PHC in Jiaozhou Bay
}

\author{
Dongfang Yang ${ }^{1,2,3, a}$, Zhenqing Miao, 2, b, Jianxun Chai ${ }^{1,2}$, Ming Wang ${ }^{1,2}$, Sixi Zhu ${ }^{1,2}$ \\ ${ }^{1}$ Research Center for Karst Wetland Ecology, Guizhou Minzu University, Guiyang 550025, China \\ ${ }^{2}$ College of Chemistry and Environmental Science, Guizhou Minzu University, Guiyang 550025, China \\ ${ }^{3}$ North China Sea Environmental Monitoring Center, SOA, Qingdao 266033, China. \\ adfyang_dfyang@126.com, ${ }^{\mathrm{b}}$ corresponding author
}

Keywords: Petroleum hydrocarbon, Distribution, Source, Migration path

\begin{abstract}
This paper analyzed the sources and migration paths of Petroleum hydrocarbon (PHC) in Jiaozhou Bay in 1987. Results showed that PHC contents in May, July and November 1987 in surface waters in Jiaozhou Bay were 0.014-0.060 mg L-1 $0.016-0.066 \mathrm{mg} \mathrm{L}^{-1}$ and 0.030-0.091 mg $\mathrm{L}^{-1}$, respectively. The pollution levels of PHC in this bay were still slight in 1987. The major PHC sources in Jiaozhou Bay in 1987 were river flow and oil port, whose source strengths were 0.066 $\mathrm{mg} \mathrm{L}^{-1}$ and $0.060-0.091 \mathrm{mg} \mathrm{L}^{-1}$, respectively. The migration paths of PHC from different sources were also different since the source strengths and geographic locations of these sources were different. In general, different countermeasures should be provided to different sources of PHC.
\end{abstract}

\section{Introduction}

With the rapid development of economic and growth of population, the production and consumption of PHC in China were increasing rapidly in the past three decades. A large amount of PHC containing wastes was generated and discharged to the environment, and many marine bays have been polluted by PHC since the ocean was the sink of various pollutants [1-6]. Hence, understanding the sources and migration paths of PHC in marine bay is essential for marine environmental protection. Jiaozhou Bay is a semi-closed bay located in south of Shandong Peninsula, eastern China, which has been polluted by many pollutants including PHC after 1980s [7-11]. The aim of this paper was to analyze the sources and migration paths PHC in this bay, and provide scientific basis for pollution control and ecosystem protection.

\section{Material and method}

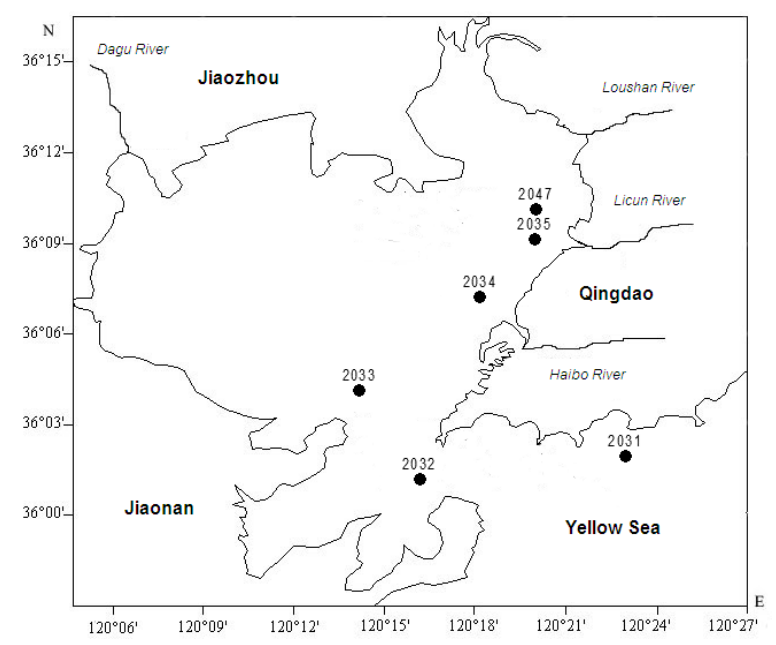

Fig.1 Geographic location and monitoring sites in Jiaozhou Bay

Jiaozhou Bay $\left(120^{\circ} 04^{\prime}-120^{\circ} 23^{\prime} \mathrm{E}, 35^{\circ} 55^{\prime}-36^{\circ} 18^{\prime} \mathrm{N}\right)$ is located in the south of Shandong Province, eastern China (Fig. 1). It is a semi-closed bay with the total area, average water depth and bay 
mouth width of $446 \mathrm{~km} 2,7 \mathrm{~m}$ and $3 \mathrm{~km}$, respectively. There are more than ten inflow rivers such as Haibo River, Licun River, Dagu River, and Loushan River [12-13]. The data were provided by North China Sea Environmental Monitoring Center. The survey was conducted in May, July and November 1987. Surface water samples in six stations (i.e. 2031, 2032, 2033, 2034, 2035 and 2047) were collected and measured followed by National Specification for Marine Monitoring [14].

\section{Results and discussion}

\subsection{Horizontal distributions of PHC}

The contents of PHC in May, July and November 1987 in surface waters in Jiaozhou Bay were 0.014-0.060 mg L-1, 0.016-0.066 mg L-1 and 0.030-0.091 mg L-1, respectively. In May 1987, high value $(0.060 \mathrm{mg} \mathrm{L}-1)$ of PHC contents occurred in Site 2032 in coastal waters in the southwest of bay, and PHC contents were decreasing from the high value center to the bay mouth (0.014 mg L-1) (Fig. 2). In July 1987, high value (0.066 mg L-1) of PHC contents occurred in Site 2047 in the estuary of Loushan River in the northeast of the bay, and PHC contents were reducing from the high value center to center of the bay $(0.046 \mathrm{mg} \mathrm{L}-1)$, the bay mouth $(0.046 \mathrm{mg} \mathrm{L}-1)$, and the open waters (0.016 mg L-1) (Fig. 3). In November 1987, high value (0.091 mg L-1) of PHC contents was occurring in Site 2033 in coastal waters in the southwest of bay, and PHC contents were decreasing from the high value center to northeast of the bay $(0.031 \mathrm{mg} \mathrm{L}-1)$, the bay mouth $(0.048 \mathrm{mg} \mathrm{L}-1)$, and the open waters $(0.038 \mathrm{mg} \mathrm{L}-1)$ (Fig. 4).

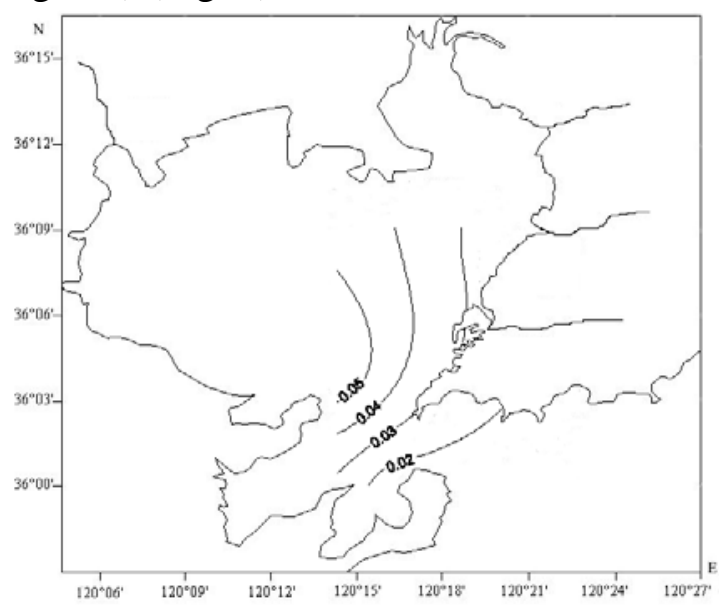

Fig. 2 Horizontal distributions of PHC in Jiaozhou Bay in May 1987/mg L-1

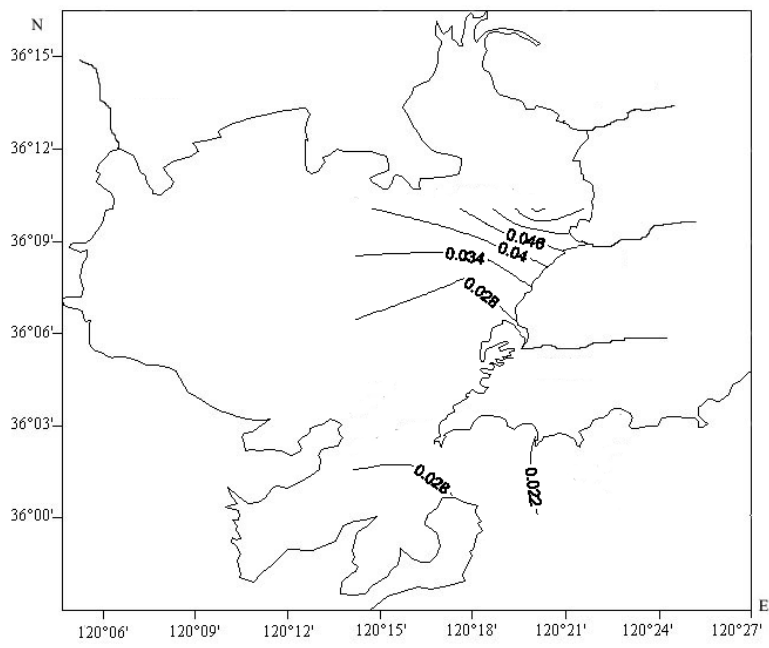

Fig. 3 Horizontal distributions of PHC in Jiaozhou Bay in July 1987/mg L-1 


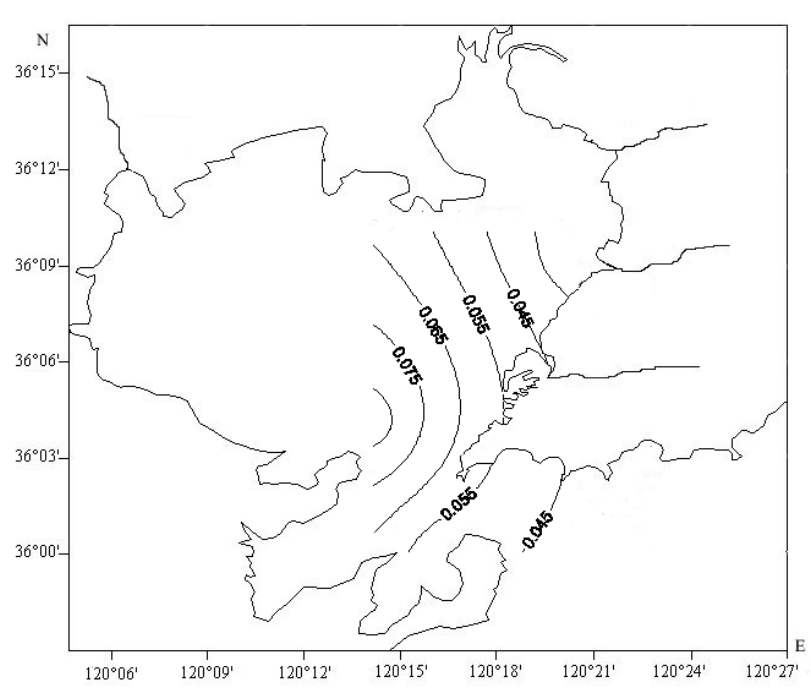

Fig. 4 Horizontal distributions of PHC in Jiaozhou Bay in November 1987/mg L-1

\subsection{Pollution levels of PHC}

According to the horizontal distributions and the guidelines of Grade I/II (0.05 mg L-1) and Grade III (0.30 mg L-1) in Chinese Sea Water Quality Standard (GB 3097-1997) for PHC, the pollution levels of PHC in Jiaozhou Bay were showing spatial variations. In May 1987, the PHC contents in coastal waters in the southwest of the bay could be as high as $0.060 \mathrm{mg} \mathrm{L}-1$, indicating that the pollution level was Grade III in this region. However, PHC contents in other regions in May 1987 were lower than $0.05 \mathrm{mg} \mathrm{L}-1$, suggesting that the pollution level was Grade I/II in these regions. In July 1987, the PHC contents in estuary of the Licun river in the northeast of the bay could be as high as $0.066 \mathrm{mg} \mathrm{L-1}$, indicating that the pollution level was Grade III in this region. However, PHC contents in other regions in July 1987 were lower than $0.05 \mathrm{mg} \mathrm{L}-1$, indicating that the pollution level was Grade I/II in these regions. In November 1987, the PHC contents in coastal waters in the southwest of the bay could be as high as $0.091 \mathrm{mg} \mathrm{L}-1$, showing that the pollution level was Grade III in this region. However, PHC contents in other regions in November 1987 were lower than $0.05 \mathrm{mg} \mathrm{L-1}$, showing that the pollution level was Grade I/II in these regions. Generally, the pollution levels of PHC in this bay were still slight in this bay in 1987.

\subsection{Sources and migration paths of PHC}

In May and November 1987, high values of PHC contents was occurring in Site 2032 and 2033 in coastal waters in the southwest of bay, in which there was a large oil port (Fig. 2 and Fig. 4). In July 1987, high value of PHC contents was occurring in Site 2047 in the estuary of Loushan River in the northeast of the bay (Fig. 3), indicating that river flow was also one of the major PHC sources. In general, the major PHC sources in Jiaozhou Bay in 1987 were river flow and oil port, whose source strengths were $0.066 \mathrm{mg} \mathrm{L}-1$ and $0.060-0.091 \mathrm{mg} \mathrm{L}-1$, respectively. A part of PHC could be discharged to the environment during the transport and storage processes, causing the high value region in the coastal waters in the southwest of the bay, and PHC could be transported and diluted along with the marine current to the northeast of the bay, the bay mouth, and the open waters (Fig. 5). Rivers were major channels of various pollutants from land to ocean, a lot of PHC was discharged to the rivers directly and was transported to the bay finally. Hence, high value region could occur in estuaries of the major rivers in the northeast of the bay, and PHC could be transported and diluted along with the marine current to the center of the bay, the bay mouth, and the open waters (Fig. 6). In a word, the migration paths of PHC from different sources were also different since the source strengths and geographic locations of these sources were different. 


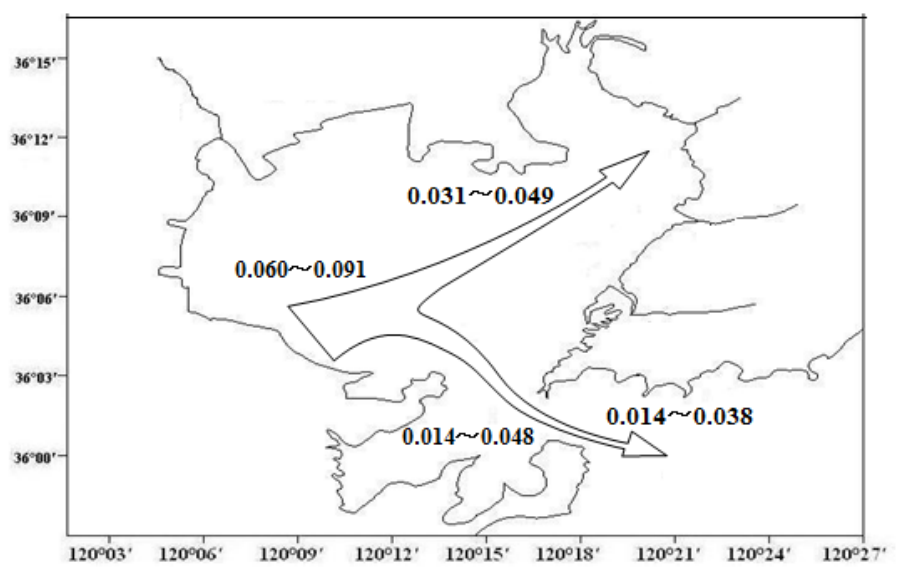

Fig. 5 Migration path of oil port sourced PHC in Jiaozhou Bay/mg L-1

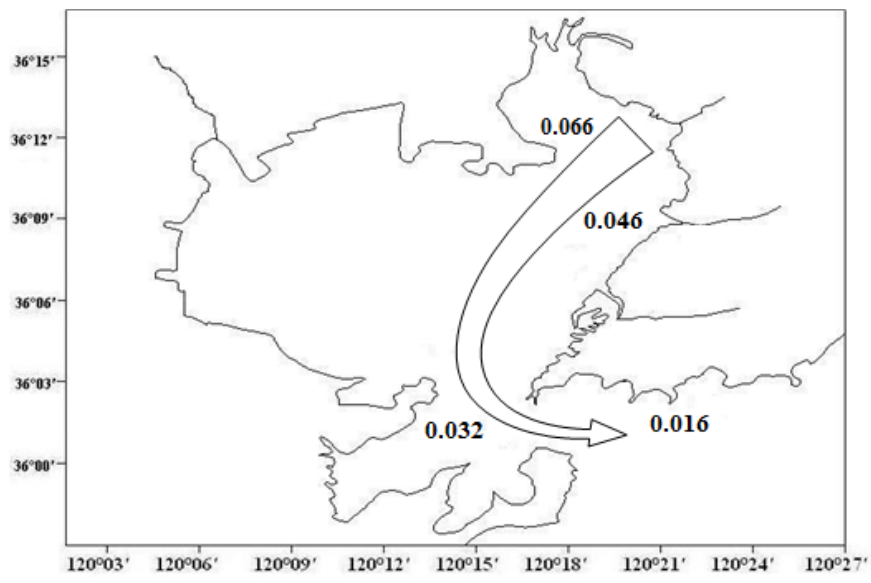

Fig. 6 Migration path of river flow sourced PHC in Jiaozhou Bay/mg L-1

\section{Conclusions}

The contents of PHC in May, July and November 1987 in surface waters in Jiaozhou Bay were 0.014-0.060 mg L-1, 0.016-0.066 mg L-1 and 0.030-0.091 mg L-1, respectively. The pollution levels of PHC in this bay were still slight in 1987. The major PHC sources in Jiaozhou Bay in 1987 were river flow and oil port, whose source strengths were $0.066 \mathrm{mg} \mathrm{L-1}$ and $0.060-0.091 \mathrm{mg} \mathrm{L-1}$, respectively. The migration paths of PHC from different sources were also different since the source strengths and geographic locations of these sources were different. For pollution control practice, different countermeasures should be provided to different sources of PHC.

\section{Acknowledgement}

This research was sponsored by Doctoral Degree Construction Library of Guizhou Nationalities University, the China National Natural Science Foundation (31560107) and Research Projects of Guizhou Nationalities University ([2014]02), Research Projects of Guizhou Province Ministry of Education (KY [2014] 266), Research Projects of Guizhou Province Ministry of Science and Technology (LH [2014] 7376).

\section{References}

[1] Yang DF, Zhang YC, Zou J, et al.: Open Journal of Marine Science, vol. 2 (2011), p. 108-112

[2] Yang DF, Sun PY, Chen C, et al.: Coastal Engineering, Vol. 32 (2013), p. 60- 72. (in Chinese)

[3] Yang DF, Sun PY, Ju L, et al.: Applied Mechanics and Materials, Vol.644-650(2014), p. 
5312-5315.

[4] Yang DF, Sun PY, Ju L, et al.: Proceedings of the 2015 international symposium on computers and informatics, vol, (2015), p. 2647-2654.

[5] Yang DF, Wang FY, Zhu SX, et al.: Proceedings of the 2015 international symposium on computers and informatics, Vol. (2015), p. 2661-2666.

[6] Yang DF, Sun PY, Ju L, et al.: Proceedings of the 2015 international symposium on computers and informatics, Vol. (2015), p. 2675-2680.

[7] Yang DF, Zhu SX, Wang FY, et al.: 4th International Conference on Energy and Environmental Protection, Vol. (2015), p. 3784-3788.

[8] Yang DF, Wang FY, Zhu SX, et al.: Advances in Engineering Research, Vol. (2015), p. 431-434.

[9] Yang DF, Wang FY, Zhu SX, et al.: Meteorological and Environmental Research, Vol. (2015), p. 31-34.

[10] Yang DF, Zhu SX, Wang FY, et al.: Advances in Engineering Research, Vol. (2016), p. 1351-1355.

[11] Yang DF, Wang FY, Zhu SX, et al.: Meteorological and Environmental Research, Vol. (2016), p. 44-47.

[12] Yang DF, Chen Y, Gao ZH, et al.: Chinese Journal of Oceanology and Limnology, Vol. 23(2005), p. 72-90.

[13] Yang DF, Wang F, Gao ZH, et al. Marine Science, Vol. 28 (2004), p. 71-74. (in Chinese)

[14] China's State Oceanic Administration: The specification for marine monitoring (Ocean Press, Beijing 1991), p.1-300. (in Chinese) 